\title{
Heterogeneous Effects of Association Between Blood Pressure Loci and Coronary Artery Disease in East Asian Individuals
}

\author{
Fumihiko Takeuchi, PhD; Masato Isono, PhD; Ken Yamamoto, MD; Mitsuhiro Yokota, MD; \\ Koichi Akiyama, PhD; Tomohiro Katsuya, MD; Hyo-Soo Kim, MD; Jeong Euy Park, MD; \\ Yangsoo Jang, MD; Ji-Young Lee, PhD; AGEN Consortium; \\ Jong-Young Lee, $\mathrm{PhD}$; Norihiro Kato, MD
}

\begin{abstract}
Background: A coronary artery disease (CAD) association study of genetic loci previously identified as being associated with blood pressure (BP) was performed in east Asian populations.
\end{abstract}

\begin{abstract}
Methods and Results: Nine single nucleotide polymorphisms (SNPs) from 9 candidate loci robustly confirmed to be associated with BP in east Asian people, were genotyped. Genotyping was done in up to 17,785 CAD casecontrol samples $(6,522$ cases and 11,263 controls). We then tested the associations with other metabolic traits ( $n \leq 17,900)$ and with type 2 diabetes (931 cases and 1,404 controls), and looked up the datasets in silico in other populations. Significant (adjusted $\mathrm{P}<0.05) \mathrm{CAD}$ associations were found for $5 \mathrm{BP}$ loci: 3 new $\mathrm{CAD}$ associations at FIGN, FGF5 and NPR3, and 2 previously reported ones at ATP2B1 and CNNM2. The strongest CAD association was detected at $A T P 2 B 1 \mathrm{rs} 2681472\left(\mathrm{P}=1.7 \times 10^{-8}\right)$, in the direction inverted to what is generally recognized for $B P$ in the epidemiological studies. CNNM2 rs12413409 showed significant association with $\mathrm{CAD}\left(\mathrm{P}=8.7 \times 10^{-7}\right)$ and $\mathrm{BMI}$ $\left(\mathrm{P}=3.5 \times 10^{-8}\right.$, when meta-analyzed with 75,807 east Asian people). The genetic risk score combining $\mathrm{BP}$-raising alleles at each of the SNPs was positively associated with CAD $(P=0.011)$.
\end{abstract}

Conclusions: A substantial proportion of genetic variants associated with BP were also associated with the risk of CAD in east Asian people, and there was some counter-evidence for causal inference. (Circ J 2015; 79: 830-838)

Key Words: Blood pressure; Coronary artery disease; Genetic susceptibility

$\mathbf{G}$ enetic, environmental and demographic factors and their interaction determine an individual's risk for hypertension, one of the most common disorders; essential hypertension may consist of disparate mechanisms that lead to elevations in systemic blood pressure (BP). Until recently, the inherently complex nature of hypertension had hampered progress in the elucidation of the genes involved, despite considerable efforts made in the study of molecular genetics of hypertension. ${ }^{1}$ With the remarkable progress in molecular techniques, genome-wide association (GWA) stud- ies involving tens of thousands of individuals have succeeded in the identification of more than $40 \mathrm{BP}$ loci, most of which are located near genes previously unsuspected in the BP regulation or in the intergenic regions. ${ }^{2,3}$

\section{Editorial p 756}

Elevated BP is related to an increased risk of cardiovascular conditions such as coronary artery disease (CAD) in the population at large. ${ }^{4,5}$ Given that there is substantial evidence for

Received July 30, 2014; revised manuscript received December 10, 2014; accepted December 16, 2014; released online February 5, 2015 Time for primary review: 14 days

Department of Gene Diagnostics and Therapeutics, Research Institute, National Center for Global Health and Medicine, Tokyo (F.T., M.I., K.A., N.K.); Department of Molecular Genetics, Medical Institute of Bioregulation, Kyushu University, Fukuoka (K.Y.); Department of Genome Science, Aichi-Gakuin University, School of Dentistry, Nagoya (M.Y.); Department of Clinical Gene Therapy (T.K.), Department of Geriatric Medicine and Nephrology (T.K.), Osaka University Graduate School of Medicine, Suita, Japan; Department of Internal Medicine, Cardiovascular Center, Seoul National University Hospital, Seoul (H.-S.K.); Division of Cardiology, Samsung Medical Center, Seoul (J.E.P.); Cardiology Division, Department of Internal Medicine, Cardiovascular Genome Center, Yonsei University College of Medicine, Seoul (Y.J.); and Center for Genome Science, Korea National Institute of Health, KCDC, Chungcheongbuk-do (Ji-Young L., Jong-Young L.), Korea

Present address: NGS Division, BIO R\&D, Gyeonggi-do (Jong-Young L.), Korea

Complete list of the AGEN-BMI Consortium is provided in Appendix S1.

Mailing address: Norihiro Kato, MD, D.Phil, Department of Gene Diagnostics and Therapeutics, Research Institute, National Center for Global Health and Medicine, 1-21-1 Toyama, Shinjuku-ku, Tokyo 162-8655, Japan. E-mail: nokato@ ri.ncgm.go.jp

ISSN-1346-9843 doi:10.1253/circj.CJ-14-0841

All rights are reserved to the Japanese Circulation Society. For permissions, please e-mail: cj@j-circ.or.jp 
clinical benefit of lowering BP in the prevention or treatment of cardiovascular disease ${ }^{6}$ it is generally assumed that single nucleotide polymorphism (SNP) alleles that increase BP are associated with an increased risk of $\mathrm{CAD}$, in proportion to the genetic effects on BP. A large-scale study has recently reported that this assumption holds true for the overall effect of BPassociated polymorphisms in people of European descent (from the CARDIoGRAM ${ }^{7}$ data set), where 23 of $26(88 \%)$ tested SNPs were associated with odds ratio $(\mathrm{OR})>1$ for CAD in a direction consistent with their effect on BP. ${ }^{8}$ We have found, however, that this is not always pertinent to a BP locus in east Asian people; at $12 \mathrm{q} 24.13$ near $A L D H 2$, the SNP alleles associated with elevated BP have turned out to be associated with a reduced risk of CAD. ${ }^{9}$ While these appear to be counterintuitive based on what is known about the relationship between $\mathrm{BP}$ and $\mathrm{CAD}$, such observations are due, in part, to pleiotropic effects: that is, the deleterious effects of the variant (at 12q24.13) on BP were balanced by protective effects on highdensity lipoprotein cholesterol (HDL-C) and low-density lipoprotein cholesterol (LDL-C).

In the present study, to further address this issue, we performed a CAD case-control study for candidate SNPs that had significant evidence for BP association in east Asian people, in a total of 6,522 cases and 11,263 controls from Japanese and Korean populations. We also examined the relevance of 9 SNPs to other cardiovascular risk traits in Japanese individuals in order to test the potential presence of pleiotropy.

\section{Methods}

\section{Case-Control Association Study for CAD}

A case-control association study for CAD was performed in a multi-tier design. Detailed characteristics of the individuals analyzed in each tier are described in Table 1. All participants were of east Asian ancestry; tier 1 and tier 2 panels were Japanese and the tier 3 panel was Korean. In the Japanese panels (tier 1 and tier 2), case subjects were enrolled from clinical practices or annual medical checkups at medical institutions and university hospitals in accordance with the uniformly defined criteria. ${ }^{10}$ These criteria included (1) a validated history of either myocardial infarction (MI) or coronary revascularization (coronary artery bypass grafting or percutaneous coronary intervention); or (2) subjective symptoms of angina pectoris with 1 or more major coronary vessels having $\geq 75 \%$ stenosis on coronary angiography. In the Korean panel (tier 3), case subjects were enrolled from teaching hospitals according to the GenRIC working group criteria. ${ }^{11}$ In all panels, controls were individuals randomly selected from a cross-sectional study of cardiovascular risk factors in the recruitment areas and were deemed free of MI on history, physical examination, and electrocardiogram.

Following the current standard of testing SNP-trait association for common disease such as CAD, we performed a meta-analysis of effect sizes in multiple groups: Japanese GWA-scanned samples and Japanese validation samples, ${ }^{10}$ and Korean GWA-scanned samples, ${ }^{11}$ for the 9 target SNP, which were first chosen, based on the results for east Asian GWA meta-analysis of BP, ${ }^{9}$ as listed in the following section. Because the major purpose was to test association between a selected list of SNP with the strongest association signal with a primary target trait (ie, BP) at individual loci, and a secondary target trait (ie, CAD), the present study was designed as such, in accordance with the previous study in European-descent people. $^{8}$

\section{Metabolic Trait Association Study}

We also performed an association study of the BP-associated variants with cardiovascular risk (or metabolic) traits - body mass index (BMI), waist-to-hip ratio (WHR), blood lipid concentration, fasting plasma glucose (FPG) and HbA1c - in the general Japanese population (Table 1). Specifically, 5,331 Japanese participants (referred to hereafter as the Amagasaki Study panel) were consecutively enrolled in the populationbased setting as described previously; ${ }^{12}$ and 12,569 other Japanese participants (referred to hereafter as the Fukuoka Cohort Study panel) were randomly selected from residents aged 50-74 years in the general population. ${ }^{13}$ We further examined the genetic associations in silico with type 2 diabetes (T2D), using GWA-scanned data sets that we previously published: 931 cases and 1,404 controls. ${ }^{14}$ For the replication study of BMI association (rs12413409 at CNNM2), the results for 75,807 east Asian people from the Asian Genome Epidemiology Network (AGEN) ${ }^{15}$ were included in meta-analysis.

In the Amagasaki Study panel, blood samples that were collected after $\geq 6$-h fast and for which there were measurement data on the corresponding phenotypes, were used for tests of association with FPG $(n=4,813)$ and blood lipid concentration $(n=4,990)$. In the Fukuoka Cohort Study panel, in contrast, because blood was drawn not strictly on the condition of overnight fast, it was not used for tests of association with FPG, LDL-C or triglyceride (TG) concentration. Here, LDL-C was calculated using the Friedewald formula, with missing values assigned to individuals with TG $>400 \mathrm{mg} / \mathrm{dl}$.

All participants from the different studies provided written informed consent, and the local ethics committees approved the protocols.

\section{SNP Genotyping and Quality Control}

Apart from 806 cases and 1,337 controls (part of the tier 1 panel, genotyping done using the Infinium HumanHap550 or Human610-Quad BeadArray [Illumina, San Diego, CA, USA] as previously reported), ${ }^{10}$ Japanese samples were genotyped using the TaqMan assay (Life Technologies, Carlsbad, CA, USA) for 9 SNPs from 9 BP loci robustly confirmed $\left(\mathrm{P}<5 \times 10^{-8}\right)$ in populations of east Asian descent. ${ }^{9}$ These SNPs included rs880315 (CASZ1), rs17030613 (ST7L), rs16849225 (FIGN), rs16998073 (FGF5), rs6825911 (ENPEP), rs1173766 (NPR3), rs12413409 (CNNM2), rs2681472 (ATP2B1), and rs35444 (TBX3). The genotype distribution of all tested SNPs was in Hardy-Weinberg equilibrium $\left(\mathrm{P}>10^{-3}\right)$. We obtained successful genotyping call rates of $>99 \%$ for the whole characterized sample (across 9 SNPs) with the TaqMan assay.

Korean samples (the tier 3 panel of CAD case-control study) were genotyped as part of the Korean GWA study for CAD with the Affymetrix Genome-Wide Human SNP array 6.0. Data cleaning and analysis were performed as described elsewhere. ${ }^{11}$

\section{Statistical Analysis}

Individual SNP Association The SNPs were tested for association with dichotomous traits (CAD and T2D) and quantitative traits (BMI, WHR, blood lipid concentration, FPG, and HbA1c) using the Cochran-Armitage trend test and linear regression analysis, respectively. In the linear regression models, we adjusted BMI and WHR for sex and age classes; lipid traits for age classes separately by sex and BMI; and FPG and HbA1c for sex, age, and BMI. Age classes were defined according to age distribution in the individual panels, and included $\leq 40,41-50,51-60$, and $>60$ years for the Amagasaki Study panel, and $\leq 55,56-60,61-65,66-70$, and $>70$ years for 


\begin{tabular}{|c|c|c|c|c|c|c|c|c|}
\hline & \multirow{3}{*}{$\begin{array}{l}\text { Amagasaki } \\
\text { Study panel }\end{array}$} & \multirow{3}{*}{$\begin{array}{c}\text { Fukuoka } \\
\text { Cohort } \\
\text { Study pane }\end{array}$} & \multicolumn{6}{|c|}{ CAD case-control study panel } \\
\hline & & & \multicolumn{2}{|c|}{ Japanese tier 1} & \multicolumn{2}{|c|}{ Japanese tier 2} & \multicolumn{2}{|c|}{ Korean } \\
\hline & & & Cases & Controls & Cases & Controls & Cases & Controls \\
\hline$n$ & 5,331 & 12,569 & 1,347 & 1,337 & 3,052 & 6,335 & 2,123 & 3,591 \\
\hline$\%$ female & 39.8 & 54.9 & 22.4 & 44.7 & 22.3 & 41.1 & 38.6 & 55.7 \\
\hline BMI $\left(\mathrm{kg} / \mathrm{m}^{2}\right)$ & $23.0 \pm 3.2$ & $23.1 \pm 3.0$ & $23.8 \pm 3.2$ & $23.4 \pm 3.2$ & $23.7 \pm 3.0$ & $23.0 \pm 2.9$ & $25.3 \pm 3.0$ & $24.0 \pm 2.9$ \\
\hline $\begin{array}{l}\text { Age at recruitment } \\
\text { (years) }\end{array}$ & $47.8 \pm 12.3$ & $62.6 \pm 6.8$ & 66.3 & 65.6 & 62.7 & 62.4 & $51.6 \pm 7.5$ & $53.1 \pm 8.3$ \\
\hline $\begin{array}{l}\text { Age at first event } \\
\text { (years) }\end{array}$ & - & - & 63.3 & - & 62.7 & - & - & - \\
\hline $\begin{array}{l}\text { Former or current } \\
\text { smoker }\end{array}$ & 45.4 & 40.1 & 65.5 & 41.3 & 65.7 & 44.1 & 50.7 & 32.7 \\
\hline Hypertension ${ }^{\dagger}$ & 21.5 & 56.9 & 65.2 & 44.8 & 53.7 & 50.1 & - & - \\
\hline $\mathrm{SBP}(\mathrm{mmHg})$ & $124.3 \pm 17.3$ & $138.8 \pm 21.2$ & - & - & - & - & $125.0 \pm 20.5$ & $122.5 \pm 14.3$ \\
\hline $\mathrm{DBP}(\mathrm{mmHg})$ & $75.9 \pm 11.0$ & $83.9 \pm 11.7$ & - & - & - & - & $77.3 \pm 12.1$ & $77.7 \pm 9.9$ \\
\hline Diabetes mellitus $\ddagger$ & 5.2 & 7.6 & 47.9 & 25.5 & 37.9 & 16.7 & - & - \\
\hline $\mathrm{FPG}(\mathrm{mmol} / \mathrm{L})$ & $5.37 \pm 0.98$ & - & - & - & - & - & - & - \\
\hline $\operatorname{HbA1c}(\%)^{n}$ & $5.26 \pm 0.53$ & $5.23 \pm 0.77$ & - & - & - & - & - & - \\
\hline Dyslipidemia§,t† & 41.3 & - & 56.7 & 54.8 & 51.9 & 49.9 & 68.5 & 46.9 \\
\hline $\begin{array}{l}\text { Total cholesterol } \\
\text { (mg/dl) }\end{array}$ & $206.9 \pm 35.2$ & $215.0 \pm 35.0$ & - & - & - & - & $180.1 \pm 44.0$ & $196 \pm 35.0$ \\
\hline LDL-C (mg/dl) $)^{\dagger \dagger}$ & $123.2 \pm 31.2$ & - & $107.1 \pm 29.7$ & $124.1 \pm 30.9$ & - & - & $110.4 \pm 41.1$ & $119.2 \pm 31.7$ \\
\hline HDL-C (mg/dl) & $62.8 \pm 17.7$ & $62.5 \pm 16.8$ & $51.2 \pm 14.1$ & $61.0 \pm 16.6$ & - & - & $42.5 \pm 10.6$ & $54.7 \pm 13.3$ \\
\hline $\mathrm{TG}(\mathrm{mg} / \mathrm{dl})$ & $110.1 \pm 87.5$ & $146.6 \pm 99.3$ & $155.1 \pm 83.9$ & $118.7 \pm 68.9$ & - & - & $161.6 \pm 109.4$ & $123.4 \pm 92.1$ \\
\hline Alcohol drinking & & & - & - & - & - & - & - \\
\hline None or abstainer & 24.1 & 53.6 & - & - & - & - & - & - \\
\hline Drinker & 75.9 & 46.4 & - & - & - & - & - & - \\
\hline
\end{tabular}

Data given as mean \pm SD or \%. All clinical assessments were performed using uniform standards in each population. Blood samples were taken after $\geq 6$-h fast in the Amagasaki Study panel; without setting strict fasting condition in the Fukuoka Cohort Study panel. †SBP

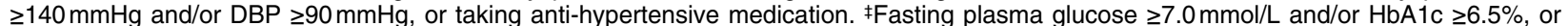
taking blood glucose-lowering medication. \$Defined according to the Japan Atherosclerosis Society Guidelines. ${ }^{30} \mathrm{M} \mathrm{HbA} 1 \mathrm{C}$ was measured for 596 subjects in the Amagasaki Study panel, whereas for all participants in the Fukuoka Cohort Study panel. $+{ }^{+} L D L-C$ was calculated in the Amagasaki Study panel using the Friedewald formula, with missing values assigned to individuals with TG $>400 \mathrm{mg} / \mathrm{dl}$. Given that blood samples were taken without setting strict fasting condition, LDL-C and the prevalence of dyslipidemia are not shown for the Fukuoka Cohort Study panel according to the Japan Atherosclerosis Society Guidelines. ${ }^{30} \mathrm{BMI}$, body mass index; CAD, coronary artery disease; DBP, diastolic blood pressure (BP); HDL-C, high-density lipoprotein cholesterol; LDL-C, low-density lipoprotein cholesterol; FPG, fasting plasma glucose; SBP, systolic BP; TG, triglycerides.

the Fukuoka Cohort Study panel. HDL-C, TG, and HbA1c were log-transformed before linear regression analysis. Significance was set at $\mathrm{P}<0.05$ after adjustment for multiple testing with Bonferroni correction. For a CAD association study, we combined association results for Japanese and Korean samples using the inverse variance method to meta-analyze effect sizes in multiple populations; we pooled association results from 2 tiers of Japanese samples, because we found no significant regional differences in the allele frequencies at 9 tested loci in Japanese. ${ }^{10}$ We used PLINK, ${ }^{16} \mathrm{R}$ (version 2.10.0; http:// cran.r-project.org/), and the rmeta and meta packages to test for the associations.

Estimation of Predicted Effect of BP-Associated SNPs on CAD We calculated the predicted effect size for each BPassociated SNP on CAD risk, based on the association between $\mathrm{BP}$ level and the incident risk of CAD (or MI) estimated on meta-analysis of Japanese cohort studies ${ }^{17}$ and the reported effects of the selected SNPs on BP level. ${ }^{9}$ In this calculation, we corrected for measurement error or within-person variability (i.e. regression dilution bias), as described previously. ${ }^{18}$ For each BP-associated SNP, the type of lead BP traits (either systolic BP [SBP] or diastolic BP [DBP]) was determined following the previous report.'

Genetic Risk Score To assess association of the variants in aggregate with prevalent $\mathrm{CAD}$, we created a genetic risk score. The risk score was weighted using the average of SBP and DBP effects $[(\mathrm{SBP} \text { effect+DBP effect }) / 2]^{3}$ for the 9 SNPs previously reported in east Asian people. ${ }^{9}$

\section{Results}

\section{Association With CAD at BP Loci}

In this study, we tested CAD associations at 9 SNP loci that had attained genome-wide significance $\left(\mathrm{P}<5 \times 10^{-8}\right)$ in previous GWA meta-analysis for BP in east Asian people. ${ }^{9}$ In the combined sample (6,522 cases and 11,263 controls; Table 2), we found a significant CAD association for 5 SNPs $(\mathrm{P}<0.0056 \approx 0.05 / 9)$ : they were rs16849225 (FIGN), rs 16998073 (FGF5), rs1173766 (NPR3), rs12413409 (CNNM2), and rs2681472 (ATP2B1). All of these had nominally significant association in both Japanese and Korean populations (Table 2; $\mathrm{P}<0.05)$. The effect sizes of association with CAD were almost identical across the study panels (tier 1, tier 2, and tier 3) (Tables 2,S1). Regional plots were done for 3 loci with prominent CAD association: FIGN, CNNM2 and ATP2B1 (Figure S1).

To assess heterogeneity in effect sizes across 3 populations (Japanese tier 1, including GWA-scanned samples, and tier 2 
Table 2. Effects of BP-Associated SNPs on CAD

\begin{tabular}{|c|c|c|c|c|c|c|c|c|c|}
\hline \multirow{3}{*}{ SNP } & \multirow{3}{*}{ Chr } & \multirow{3}{*}{$\begin{array}{l}\text { Position } \\
\text { (Build 36) }\end{array}$} & \multirow{3}{*}{$\begin{array}{l}\text { Nearby } \\
\text { gene(s) }\end{array}$} & \multirow{3}{*}{$\begin{array}{c}\text { Alleles } \\
\text { (coded/other) }\end{array}$} & \multicolumn{5}{|c|}{ Japanese } \\
\hline & & & & & \multicolumn{2}{|c|}{$\begin{array}{c}\text { Coded allele } \\
\text { frequency }\end{array}$} & \multirow{2}{*}{$\begin{array}{c}\text { OR } \\
(95 \% \mathrm{Cl})\end{array}$} & \multirow[t]{2}{*}{ P-value } & \multirow[t]{2}{*}{$\mathrm{n}$ total } \\
\hline & & & & & Case & Control & & & \\
\hline rs880315 & 1 & $10,719,453$ & CASZ1 & $\mathrm{C} / \mathrm{T}$ & 0.677 & 0.685 & $\begin{array}{c}0.96 \\
(0.91-1.02)\end{array}$ & 0.214 & 12,048 \\
\hline rs17030613 & 1 & $112,992,330$ & $S T 7 L$ & $\mathrm{C} / \mathrm{A}$ & 0.490 & 0.497 & $\begin{array}{c}0.97 \\
(0.92-1.03)\end{array}$ & 0.345 & 12,032 \\
\hline rs16849225 & 2 & $164,615,066$ & FIGN & $\mathrm{C} / \mathrm{T}$ & 0.643 & 0.618 & $\begin{array}{c}1.12 \\
(1.06-1.18)\end{array}$ & $6.6 \mathrm{E}-05$ & 12,057 \\
\hline rs16998073 & 4 & $81,403,365$ & FGF5 & T/A & 0.315 & 0.300 & $\begin{array}{c}1.07 \\
(1.01-1.14)\end{array}$ & 0.015 & 12,049 \\
\hline rs6825911 & 4 & $111,601,087$ & ENPEP & $\mathrm{C} / \mathrm{T}$ & 0.553 & 0.541 & $\begin{array}{c}1.05 \\
(1.00-1.11)\end{array}$ & 0.057 & 12,049 \\
\hline rs1173766 ${ }^{\dagger}$ & 5 & $32,840,285$ & NPR3 & $\mathrm{C} / \mathrm{T}$ & 0.592 & 0.578 & $\begin{array}{c}1.06 \\
(1.01-1.12)\end{array}$ & 0.030 & 12,020 \\
\hline rs12413409 & 10 & $104,709,086$ & CNNM2 & $\mathrm{G} / \mathrm{A}$ & 0.754 & 0.732 & $\begin{array}{c}1.12 \\
(1.06-1.19)\end{array}$ & $1.8 \mathrm{E}-04$ & 12,059 \\
\hline rs2681472 & 12 & $88,533,090$ & ATP2B1 & $\mathrm{T} / \mathrm{C}$ & 0.594 & 0.628 & $\begin{array}{c}0.87 \\
(0.82-0.91)\end{array}$ & $2.5 \mathrm{E}-07$ & 12,007 \\
\hline rs35444t & 12 & $114,036,820$ & TBX3 & $A / G$ & 0.753 & 0.739 & $\begin{array}{c}1.07 \\
(1.01-1.14)\end{array}$ & 0.020 & 12,006 \\
\hline
\end{tabular}

\begin{tabular}{|c|c|c|c|c|c|c|c|c|}
\hline \multirow{3}{*}{ SNP } & \multicolumn{5}{|c|}{ Korean } & \multicolumn{3}{|c|}{ Combined } \\
\hline & \multicolumn{2}{|c|}{$\begin{array}{c}\text { Coded allele } \\
\text { frequency }\end{array}$} & \multirow{2}{*}{$\begin{array}{c}\text { OR } \\
(95 \% \mathrm{Cl})\end{array}$} & \multirow[t]{2}{*}{ P-value } & \multirow[t]{2}{*}{$\mathrm{n}$ total } & \multirow{2}{*}{$\begin{array}{c}\text { OR } \\
(95 \% \mathrm{Cl})\end{array}$} & \multirow[t]{2}{*}{ P-value } & \multirow[t]{2}{*}{$\mathbf{N}$} \\
\hline & Case & Control & & & & & & \\
\hline rs880315 & N/A & & & & & $\begin{array}{c}0.96 \\
(0.91-1.02)\end{array}$ & 0.214 & 12,048 \\
\hline rs 17030613 & 0.500 & 0.510 & $\begin{array}{c}0.930 \\
(0.86-1.00)\end{array}$ & 0.060 & 5,685 & $\begin{array}{c}0.96 \\
(0.92-1.00)\end{array}$ & 0.066 & 17,717 \\
\hline rs 16849225 & 0.610 & 0.600 & $\begin{array}{c}1.140 \\
(1.05-1.23)\end{array}$ & 0.002 & 5,619 & $\begin{array}{c}1.12 \\
(1.08-1.18)\end{array}$ & 2.2E-07 & 17,676 \\
\hline rs16998073 & 0.36 & 0.330 & $\begin{array}{c}1.12 \\
(1.03-1.22)\end{array}$ & 0.008 & 5,315 & $\begin{array}{c}1.09 \\
(1.04-1.14)\end{array}$ & 6.3E-04 & 17,364 \\
\hline rs6825911 & 0.493 & 0.483 & $\begin{array}{c}1.040 \\
(0.96-1.13)\end{array}$ & 0.334 & 5,417 & $\begin{array}{c}1.05 \\
(1.00-1.10)\end{array}$ & 0.033 & 17,466 \\
\hline rs $1173766^{\dagger}$ & 0.619 & 0.597 & $\begin{array}{c}1.10 \\
(1.01-1.19)\end{array}$ & 0.018 & 5,594 & $\begin{array}{c}1.07 \\
(1.03-1.12)\end{array}$ & 0.002 & 17,614 \\
\hline rs12413409 & 0.776 & 0.751 & $\begin{array}{c}1.15 \\
(1.05-1.26)\end{array}$ & 0.004 & 5,690 & $\begin{array}{c}1.13 \\
(1.08-1.19)\end{array}$ & 8.7E-07 & 17,749 \\
\hline rs2681472 & 0.590 & 0.610 & $\begin{array}{c}0.92 \\
(0.85-1.00)\end{array}$ & 0.037 & 5,458 & $\begin{array}{c}0.88 \\
(0.84-0.92)\end{array}$ & 1.7E-08 & 17,465 \\
\hline rs $35444^{\dagger}$ & 0.760 & 0.750 & $\begin{array}{c}1.04 \\
(0.95-1.14)\end{array}$ & 0.318 & 5,690 & $\begin{array}{c}1.06 \\
(1.01-1.12)\end{array}$ & 0.015 & 17,696 \\
\hline
\end{tabular}

A CAD association study comprises 2 sample populations: the Japanese sample (4,399 cases and 7,672 controls) and the Korean sample ( 2,123 cases and 3,591 controls). In the Japanese, association results from the 2 tiers were combined by pooling the genotype counts (Table S1), given that we found no significant regional differences in the allele frequencies at 9 tested loci in the Japanese sample. ${ }^{10}$ Association results for the Japanese and Korean subjects were combined using inverse variance weighting with the rmeta package of R. †In part of the tier 1 panel ( 806 cases and 1,337 controls), proxy SNPs were genotyped at ENPEP (rs6825911 is replaced by rs $4358460, \mathrm{r}^{2}=1.000$ in HapMap $\mathrm{JPT}+\mathrm{CHB}$ ), NPR3 (rs1173766 is replaced by rs1147225, $\mathrm{r}^{2}=0.952$ in JPT+CHB), and TBX3 (rs35444 is replaced by rs35441, $\mathrm{r}^{2}=0.883$ in $\mathrm{JPT}+\mathrm{CHB}$ ). $¥$ Alleles associated with elevated BP are defined as coded. Alleles are nominated as those in dbSNP Build 130 mapped on the strand of Human Genome Build 36.3. SNP, single nucleotide polymorphism. Other abbreviations as in Table 1.

(validation samples) panels, and Korean GWA-scanned samples), we prepared forest plots and analyzed Cochran's Q-test for the 9 SNPs; we found a lack of significant evidence for heterogeneity at 5 significantly associated SNPs (Figure S2).

Among the 5 significant SNP loci, the T-allele of rs2681472 at $A T P 2 B 1$, associated with elevated $\mathrm{BP}$, was found to be associated with a reduced risk of CAD (OR, 0.88; 95\% CI: $0.84-0.92, \mathrm{P}=1.7 \times 10^{-8}$ in the combined sample; Table 2 ). To evaluate the inter-trait correlation, we then produced scatter plots (Figure 1) and observed that, for 9 BP-associated SNP loci, there was no apparent correlation of effect sizes between SBP and CAD; and there was a fair correlation of effect sizes between SBP and DBP.

To examine the possibility that CAD association of BP loci reflects a causal relationship of increasing $\mathrm{BP}$ with $\mathrm{CAD}$, we displayed the predicted effect and the observed effect (both 
A

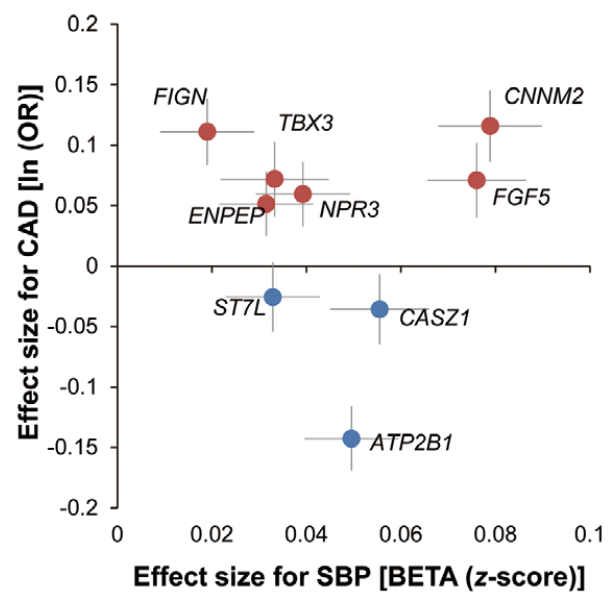

B

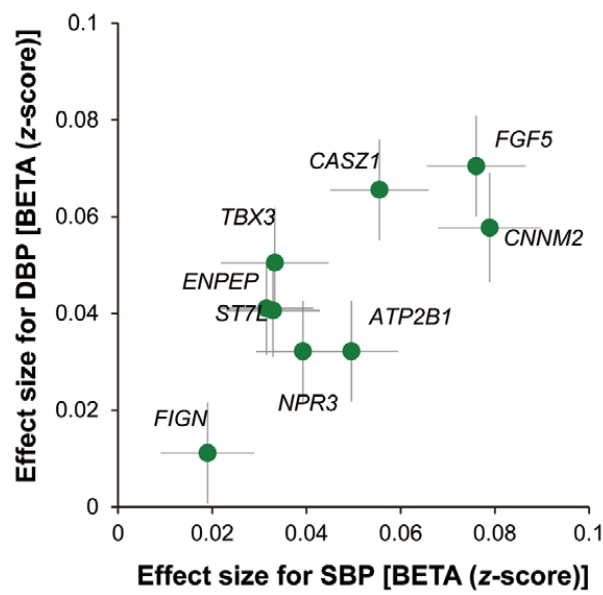

Figure 1. Correlation of effect sizes for coronary artery disease (CAD) risk and blood pressure (BP traits at 9 loci tested in the current study: (A) CAD vs. systolic BP (SBP); and (B) SBP vs. diastolic BP (DBP). Genetic impacts on BP ( $\beta$ ) and CAD risk (odds ratio, OR) are compared for the 9 SNP loci that were previously reported to be associated with BP in east Asian people (Table 2). ${ }^{9}$ Whiskers represent $95 \% \mathrm{Cl}$. Effect sizes for SBP and DBP were derived from meta-analysis in samples from Amagasaki and Fukuoka Cohort Study panels, and those for CAD were from meta-analysis in samples from the tier 1 and tier 2 Japanese panels.
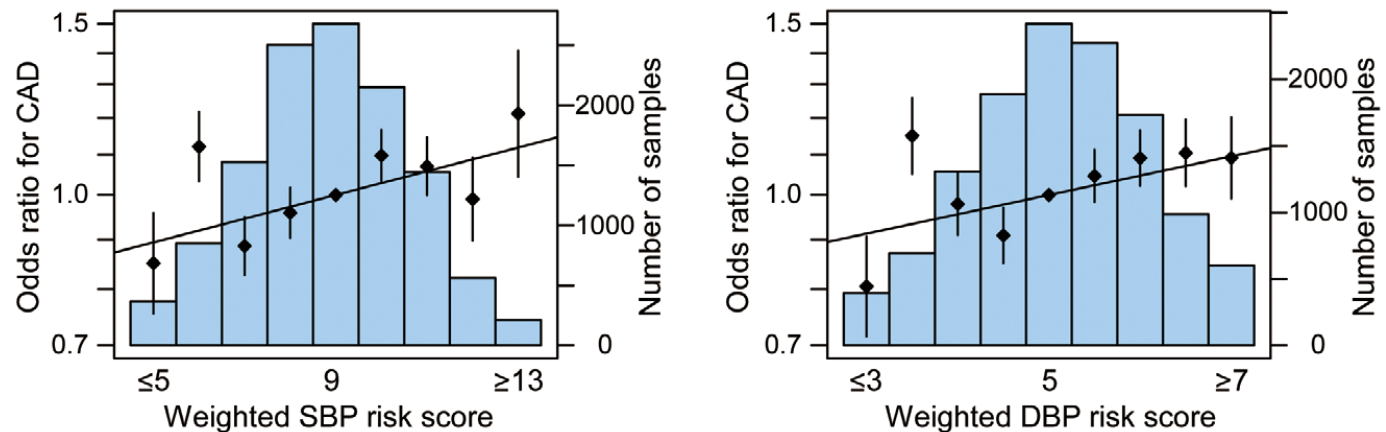

Figure 2. Genetic risk scores (OR, $\bullet$ ) for coronary artery disease (CAD) for (Left) systolic blood pressure (SBP) and (Right) diastolic blood pressure (DBP). Whiskers, \pm 1 SE. Blue bars, sample size for BP risk score groups. The P-values for slope across $B P$ risk score groups were significant: $P=0.009$ and $P=0.017$ for SBP and DBP risk scores, respectively, and $P=0.011$ for the average of SBP and DBP effects (for all BP effects: OR, 1.05; 95\% Cl: 1.01-1.09; per 1-SD effect of risk score).

quantified as OR) of each individual SNP on CAD (Figure S3). The predicted effects of 9 SNPs were in the range $\mathrm{OR}=1.01-$ 1.03 and showed substantial disagreement with their observed effects, suggesting that some of the association between BP loci and CAD is likely through non-BP-mediated pathways genetically determined.

The genetic risk score was positively associated with CAD $(\mathrm{P}=0.011$; OR, 1.05 ; 95\% CI: $1.01-1.09$ per $1 \mathrm{SD}$ increase in the average of SBP and DBP effects) in the Japanese CAD case-control panels (Figure 2).

Genetic Associations With Other Cardiovascular Risk Traits Assuming the presence of pleiotropy, we examined the asso- ciation of the 9 SNPs with other cardiovascular risk traits in Japanese individuals (Table 3). After adjustment for multiple testing, there were 3 significant association signals: at rs 12413409 (CNNM2) for BMI, and at rs880315 (CASZ1) and rs1173766 $(N P R 3)$ for $\mathrm{HbA} 1 \mathrm{c}(\mathrm{P}<0.0056 \approx 0.05 / 9)$. The association between rs12413409 and BMI was replicated in an independent large sample of east Asian people $(n=75,807 ; \beta,-0.0365$; SE, $\left.0.008 ; \mathrm{P}=2.5 \times 10^{-6}\right)$, reaching genome-wide significance when meta-analyzed $\left(\mathrm{n}=93,707 ; \beta,-0.0358 ; \mathrm{SE}, 0.006 ; \mathrm{P}=3.5 \times 10^{-8}\right)$. Notably, the direction of this BMI association appeared to be counterintuitive in terms of CAD risk. That is, the G-allele of rs12413409 associated with elevated BP was associated with reduction of BMI, whereas it was associated with an increased 


\begin{tabular}{|c|c|c|c|c|c|c|c|c|c|c|c|c|}
\hline \multirow{3}{*}{ SNP ID } & \multirow{3}{*}{ Chr } & \multirow{3}{*}{$\begin{array}{l}\text { Position } \\
\text { (Build 36) }\end{array}$} & \multirow{3}{*}{$\begin{array}{l}\text { Coded/ } \\
\text { Other } \\
\text { allele }\end{array}$} & \multirow{3}{*}{ CAF } & \multicolumn{4}{|c|}{ Obesity measure } & \multicolumn{4}{|c|}{ Lipid } \\
\hline & & & & & \multicolumn{2}{|c|}{$\begin{array}{c}\text { BMI } \\
\left(\mathrm{kg} / \mathrm{m}^{2}\right)\end{array}$} & \multicolumn{2}{|c|}{ WHR } & \multicolumn{2}{|c|}{$\begin{array}{c}\begin{array}{c}\text { Total cholesterol } \\
\text { (mg/dl) }\end{array} \\
\end{array}$} & \multicolumn{2}{|c|}{$\begin{array}{l}\text { LDL-C } \\
(\mathrm{mg} / \mathrm{dl})\end{array}$} \\
\hline & & & & & $\beta$ (SE) & P-value & $\beta$ (SE) & P-value & $\beta$ (SE) & P-value & $\beta$ (SE) & P-value \\
\hline rs880315 & 1 & $10,719,453$ & $\mathrm{C} / \mathrm{T}$ & 0.66 & $\begin{array}{l}-0.007 \\
(0.011)\end{array}$ & 0.520 & $\begin{array}{l}-0.002 \\
(0.013)\end{array}$ & 0.857 & $\begin{array}{l}-0.132 \\
(0.394)\end{array}$ & 0.739 & $\begin{array}{l}-0.120 \\
(0.620)\end{array}$ & 0.847 \\
\hline rs17030613 & 1 & $112,971,190$ & $\mathrm{C} / \mathrm{A}$ & 0.49 & $\begin{array}{l}0.003 \\
(0.010)\end{array}$ & 0.810 & $\begin{array}{l}-0.006 \\
(0.012)\end{array}$ & 0.599 & $\begin{array}{c}0.129 \\
(0.371)\end{array}$ & 0.728 & $\begin{array}{c}0.435 \\
(0.592)\end{array}$ & 0.463 \\
\hline rs16849225 & 2 & $164,615,066$ & $\mathrm{C} / \mathrm{T}$ & 0.61 & $\begin{array}{l}-0.022 \\
(0.011)\end{array}$ & 0.036 & $\begin{array}{l}-0.027 \\
(0.013)\end{array}$ & 0.033 & $\begin{array}{c}0.058 \\
(0.380)\end{array}$ & 0.879 & $\begin{array}{c}0.104 \\
(0.595)\end{array}$ & 0.861 \\
\hline rs16998073 & 4 & $81,541,520$ & T/A & 0.31 & $\begin{array}{l}-0.011 \\
(0.011)\end{array}$ & 0.333 & $\begin{array}{l}0.0001 \\
(0.013)\end{array}$ & 0.992 & $\begin{array}{l}-0.392 \\
(0.404)\end{array}$ & 0.332 & $\begin{array}{c}0.341 \\
(0.642)\end{array}$ & 0.595 \\
\hline rs6825911 & 4 & $111,601,087$ & $\mathrm{C} / \mathrm{T}$ & 0.53 & $\begin{array}{l}-0.005 \\
(0.010)\end{array}$ & 0.658 & $\begin{array}{l}-0.010 \\
(0.012)\end{array}$ & 0.402 & $\begin{array}{c}0.240 \\
(0.373)\end{array}$ & 0.520 & $\begin{array}{c}0.764 \\
(0.590)\end{array}$ & 0.196 \\
\hline rs1173766 & 5 & $32,840,285$ & $\mathrm{C} / \mathrm{T}$ & 0.58 & $\begin{array}{l}0.014 \\
(0.011)\end{array}$ & 0.191 & $\begin{array}{c}0.011 \\
(0.012)\end{array}$ & 0.394 & $\begin{array}{l}-0.179 \\
(0.380)\end{array}$ & 0.637 & $\begin{array}{l}-0.227 \\
(0.601)\end{array}$ & 0.706 \\
\hline rs12413409 & 10 & $104,709,086$ & $\mathrm{G} / \mathrm{A}$ & 0.73 & $\begin{array}{l}-0.035 \\
(0.012)\end{array}$ & 0.003 & $\begin{array}{l}-0.015 \\
(0.014)\end{array}$ & 0.262 & $\begin{array}{c}0.314 \\
(0.417)\end{array}$ & 0.452 & $\begin{array}{l}-0.239 \\
(0.666)\end{array}$ & 0.719 \\
\hline rs2681472 & 12 & $88,533,090$ & $\mathrm{~T} / \mathrm{C}$ & 0.64 & $\begin{array}{c}0.012 \\
(0.011)\end{array}$ & 0.268 & $\begin{array}{c}0.007 \\
(0.012)\end{array}$ & 0.262 & $\begin{array}{l}-0.270 \\
(0.383)\end{array}$ & 0.481 & $\begin{array}{l}-0.879 \\
(0.615)\end{array}$ & 0.153 \\
\hline rs35444 & 12 & $114,036,820$ & $\mathrm{~A} / \mathrm{G}$ & 0.74 & $\begin{array}{l}-0.010 \\
(0.012)\end{array}$ & 0.412 & $\begin{array}{l}-0.002 \\
(0.014)\end{array}$ & 0.908 & $\begin{array}{l}-0.277 \\
(0.432)\end{array}$ & 0.521 & $\begin{array}{c}0.095 \\
(0.685)\end{array}$ & 0.889 \\
\hline
\end{tabular}

\begin{tabular}{|c|c|c|c|c|c|c|c|c|c|c|}
\hline \multirow{3}{*}{ SNP ID } & \multicolumn{4}{|c|}{ Lipid } & \multicolumn{4}{|c|}{ T2D-related trait } & \multirow{2}{*}{\multicolumn{2}{|c|}{ T2D ${ }^{\dagger}$}} \\
\hline & \multicolumn{2}{|c|}{ HDL-C (mg/dl) } & \multicolumn{2}{|c|}{$\mathrm{TG}(\mathrm{mg} / \mathrm{dl})$} & \multicolumn{2}{|c|}{ FPG (mmol/L) } & \multicolumn{2}{|c|}{ HbA1c (\%) } & & \\
\hline & $\beta$ (SE) & P-value & $\beta$ (SE) & P-value & $\beta$ (SE) & P-value & $\beta$ (SE) & P-value & OR $(95 \% \mathrm{Cl})$ & P-value \\
\hline rs880315 & $\begin{array}{c}0.002 \\
(0.001)\end{array}$ & 0.083 & $\begin{array}{l}-0.002 \\
(0.004)\end{array}$ & 0.709 & $\begin{array}{c}0.009 \\
(0.011)\end{array}$ & 0.417 & $\begin{array}{l}-0.0022 \\
(0.0007)\end{array}$ & 0.002 & $\begin{array}{c}0.97 \\
(0.85-1.10)\end{array}$ & 0.583 \\
\hline rs17030613 & $\begin{array}{c}0.002 \\
(0.001)\end{array}$ & 0.062 & $\begin{array}{l}-0.005 \\
(0.004)\end{array}$ & 0.210 & $\begin{array}{c}0.020 \\
(0.010)\end{array}$ & 0.060 & $\begin{array}{c}0.0001 \\
(0.0007)\end{array}$ & 0.902 & $\begin{array}{c}0.95 \\
(0.85-1.07)\end{array}$ & 0.404 \\
\hline rs16849225 & $\begin{array}{l}-0.001 \\
(0.001)\end{array}$ & 0.503 & $\begin{array}{c}0.001 \\
(0.004)\end{array}$ & 0.865 & $\begin{array}{l}-0.001 \\
(0.010)\end{array}$ & 0.887 & $\begin{array}{c}0.0002 \\
(0.0007)\end{array}$ & 0.814 & $\begin{array}{c}0.99 \\
(0.88-1.12)\end{array}$ & 0.881 \\
\hline rs16998073 & $\begin{array}{l}0.0001 \\
(0.001)\end{array}$ & 0.923 & $\begin{array}{l}-0.001 \\
(0.005)\end{array}$ & 0.893 & $\begin{array}{c}0.005 \\
(0.011)\end{array}$ & 0.630 & $\begin{array}{c}0.0001 \\
(0.0007)\end{array}$ & 0.902 & $\begin{array}{c}1.04 \\
(0.92-1.17)\end{array}$ & 0.563 \\
\hline rs6825911 & $\begin{array}{c}0.002 \\
(0.001)\end{array}$ & 0.207 & $\begin{array}{l}-0.004 \\
(0.004)\end{array}$ & 0.381 & $\begin{array}{c}-0.0001 \\
(0.010)\end{array}$ & 0.990 & $\begin{array}{l}-0.0002 \\
(0.0007)\end{array}$ & 0.714 & $\begin{array}{c}0.92 \\
(0.82-1.04)\end{array}$ & 0.195 \\
\hline rs1173766 & $\begin{array}{l}-0.001 \\
(0.001)\end{array}$ & 0.389 & $\begin{array}{c}0.001 \\
(0.004)\end{array}$ & 0.854 & $\begin{array}{c}0.008 \\
(0.011)\end{array}$ & 0.431 & $\begin{array}{l}-0.0019 \\
(0.0007)\end{array}$ & 0.004 & $\begin{array}{c}1.03 \\
(0.92-1.17)\end{array}$ & 0.572 \\
\hline rs12413409 & $\begin{array}{c}0.003 \\
(0.001)\end{array}$ & 0.017 & $\begin{array}{l}-0.008 \\
(0.005)\end{array}$ & 0.075 & $\begin{array}{l}-0.015 \\
(0.012)\end{array}$ & 0.209 & $\begin{array}{c}0.0009 \\
(0.0008)\end{array}$ & 0.249 & $\begin{array}{c}1.02 \\
(0.89-1.16)\end{array}$ & 0.819 \\
\hline rs2681472 & $\begin{array}{l}0.0002 \\
(0.001)\end{array}$ & 0.860 & $\begin{array}{c}-0.0001 \\
(0.004)\end{array}$ & 0.988 & $\begin{array}{l}-0.005 \\
(0.011)\end{array}$ & 0.661 & $\begin{array}{c}0.0003 \\
(0.0007)\end{array}$ & 0.662 & $\begin{array}{c}0.97 \\
(0.86-1.09)\end{array}$ & 0.579 \\
\hline rs35444 & $\begin{array}{c}0.002 \\
(0.001)\end{array}$ & 0.191 & $\begin{array}{l}-0.008 \\
(0.005)\end{array}$ & 0.116 & $\begin{array}{c}0.004 \\
(0.012)\end{array}$ & 0.767 & $\begin{array}{l}-0.0004 \\
(0.0008)\end{array}$ & 0.650 & $\begin{array}{c}1.08 \\
(0.95-1.24)\end{array}$ & 0.247 \\
\hline
\end{tabular}

Variables adjusted for in the regression models: sex and age-class in testing association with BMI and WHR; sex, age-class, and BMI in testing association with total cholesterol, LDL-C, HDL-C (log-transformed), and TG (log-transformed); and sex, age, and BMI in testing association with FPG and HbA1c (log-transformed). LDL-C was calculated in the Amagasaki Study panel $(n=5,331)$ using the Friedewald formula, with missing values assigned to individuals with $T G>400 \mathrm{mg} / \mathrm{dl}$. Given that blood samples were taken without setting strict fasting condition, LDL-C was not calculated in the Fukuoka Cohort Study panel $(n=12,569)$ according to the Japan Atherosclerosis Society Guidelines. ${ }^{30}$ TraitSNP association is meta-analyzed in samples from the Amagasaki Study (AMA; $n=5,331$ ) and Fukuoka Cohort Study (FUK; $n=12,569)$ except for FPG, LDL-C, and TG (AMA samples alone) and WHR and HbA1c (FUK samples alone). Variables adjusted in the regression models are: age classes by sex for BMI (normalized) and WHR (normalized); sex, age, age-squared and BMI for total cholesterol, LDL-C, HDL-C (log 10transformed), and TG (log 10 -transformed); and sex, age and BMI for FPG and HbA1c (log 10 -transformed). ${ }^{\dagger}$ Association with T2D is tested in the CAGE Network samples (931 cases and 1,404 controls). ${ }^{14}$ CAF, coded allele frequency; T2D, type 2 diabetes; WHR, waist-to-hip ratio. Other abbreviations as in Tables $1,2$.

risk of CAD (OR, $\left.1.13 ; 95 \% \mathrm{CI}: 1.08-1.19, \mathrm{P}=8.7 \times 10^{-7}\right)$ in the combined sample (Table 2). No significant association with HbA1c was replicated for rs880315 (CASZ1) and rs1173766 $(N P R 3)$ in a large GWA-scanned sample $(n=20,160)$ of east Asian people (data not shown).

\section{Discussion}

The present study shows that 5 common variant loci influencing BP are significantly associated with CAD in a total of 17,785 east Asian samples, with the presence of some counter- 


\section{CNNM2 \\ Present study $(n=17785)$ \\ Schunkert et al. $(n=143677)$ \\ Total $(n=161462)$

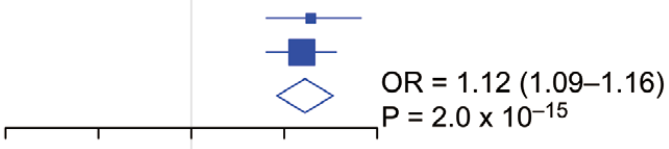 \\ ATP2B1 \\ Present study $(n=17785)$ \\ Lu et al. $(n=33196)$ \\ Total $(n=50981)$

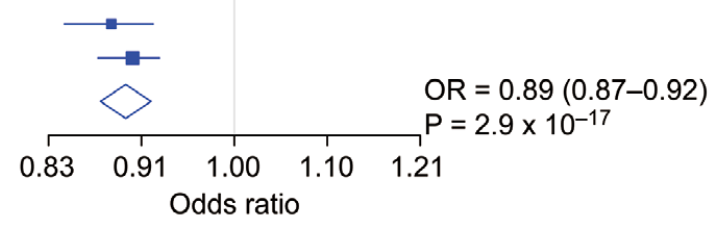 \\ Figure 3. Meta-analysis of coronary artery disease (CAD) association at 2 principal loci. At CNNM2, rs12413409 was used in both current and previously reported stud- ies. ${ }^{20}$ At ATP2B1, in contrast, rs2681472 and rs7136259 were used in the current and previous studies, ${ }^{19}$ respectively; the 2 SNPs are in fair linkage disequilibrium $\left(r^{2}=0.738, D^{\prime}=0.859\right)$ in east Asian peo- ple.}

evidence for causal inferences. Despite the small number of SNP loci tested here (9 SNPs), we found a BP locus, rs2681472 at $A T P 2 B 1$, to demonstrate a counterintuitive relationship between BP and CAD, similar to the locus at 12q24.13 (near $A L D H 2$ ) previously reported in east Asian people. ${ }^{9}$ Although the BP-associated SNPs at $12 \mathrm{q} 24.13$ showed substantial pleiotropic effects on risk factors for cardiovascular disease, it did not appear to be the case with rs2681472 at ATP2B1 for a series of risk factors tested in the present study (Table 3 ). Also, rs12413409 at CNNM2 had significant association with CAD and BMI, whereas the alleles associated with elevated $\mathrm{BP}$ and risk of $\mathrm{CAD}$ were associated with reduced BMI, suggesting the complexity in causal relationship.

For more than half of the tested BP loci (5 out of 9 SNPs), the CAD association reached significance after adjustment for multiple testing $(\mathrm{P}<0.0056)$ in the combined sample of east Asian people and also had nominal significance $(\mathrm{P}<0.05)$ concordantly in the Japanese and Korean populations (Table 2). In the previous GWA studies of CAD, ${ }^{19,20}$ a genome-wide significant association has been identified at 2 of 9 loci: $A T P 2 B 1$ and $C N N M 2$ (Figure 3). At ATP2B1, rs7136259 was shown to be associated with CAD in a Chinese GWA study; ${ }^{19}$ rs7136259 and rs2681472 were in fair linkage disequilibrium $\left(\mathrm{LD} ; \mathrm{r}^{2}=0.738, \mathrm{D}^{\prime}=0.859\right.$ ) in east Asian people (the HapMap $\mathrm{CHB}+\mathrm{JPT}$ panel). Although the counterintuitive relationship had not been recognized in the Chinese GWA study, ${ }^{19}$ the $\mathrm{T}$ allele of rs 7136259 , which is in LD with a BP-lowering allele (C-allele) of rs2681472 tested in the present study, has turned out to be associated with elevated risk of CAD. At CNNM2, in contrast, rs12413409 was shown to be associated with CAD in a meta-analysis of European GWA studies; ${ }^{20}$ the G allele of rs12413409 associated with higher BP was also associated with elevated risk of CAD and with BMI in European people, ${ }^{21}$ both of these findings were confirmed in east Asian people. Such counterintuitive associations can be explained by the potential presence of pleiotropic effects of a single allele and/or multiple genes, and alleles that affect multiple independent traits. In this line, it has been reported that the variants at the $C D K A L 1$ and $K C N Q 1$ loci are associated with an increased risk of $\mathrm{T} 2 \mathrm{D}$ as well as with decreased BMI. ${ }^{22}$ Despite the strong link between the $2 \mathrm{CAD}$-associated traits, the directions of genetic association are inverted in terms of susceptibility to CAD risk. One clinical study has suggested that suppression of insulin secretion, which can increase a risk for T2D, is associated with loss of body weight and fat mass. ${ }^{23}$ To proceed with investigation of the cause-and-effect relationships between the CAD-associated traits, the findings of the counteractive effects in the present study are also of note. For the other $7 \mathrm{BP}$ loci, little corresponding data have been provided to date with regard to CAD association, apart from the Lieb et al study, ${ }^{8}$ in which CAD association was also indicated for $F G F 5(\mathrm{P}=0.038$ at rs1458038) and $N P R 3(\mathrm{P}=0.02$ at rs 1173771) but not for FIGN ( $\mathrm{P}=0.65$ at $\mathrm{rs} 1446468)$ in European people.

Among the 5 loci thus identified as having significant $C A D$ association in east Asian people, $A T P 2 B 1$ is of particular note. Several lines of evidence have supported $A T P 2 B 1$ as a candidate causative gene for the BP association at $12 \mathrm{q} 21.3$. Besides physical proximity of lead SNP to the gene, first, ATP2B1 mRNA expression was found to be associated with genotypes of a lead SNP, rs11105738, in umbilical artery smooth muscle cells; and second, significant BP elevation was demonstrated in mice with vascular smooth muscle cell-specific knockout of ATP2B1, which was assumed through alteration of calcium handling and vasoconstriction. ${ }^{24}$ Moreover, third, an SNP (rs17249754), which is in strong LD with rs2681472 and rs11105738, was found to be associated with arterial stiffness, measured using carotid-femoral pulse wave velocities (cfPWV); ${ }^{25}$ the alleles associated with faster cf-PWV were also associated with higher BP, in accordance with their functional relationship. Although we could not find evidence for pleiotropic effects that directly or indirectly influence the outcome (ie, CAD) other than through its risk factor (ie, BP elevation) in the present study, it is possible that $A T P 2 B 1$ and/or other causative genes at $12 \mathrm{q} 21.3$ exert some unnoticed effects on the coronary artery, thereby producing a counterintuitive action based on what is known about the relationship between BP and CAD. Without eventual identification of the causal variant(s) underlying the relevant genetic associations, we cannot clearly explain the molecular mechanisms as to how BP-elevating alleles exert CAD-protective effects at $12 \mathrm{q} 21.3$ near $A T P 2 B 1$. Largely, however, 2 possibilities seem to be possible in such a case. One is that at a given locus there are multiple genes and alleles that participate in the regulation of multiple independent traits through diverse mechanisms. These multiple variants might have arisen at different times in the historical context, with each affecting CAD risk phenotypes (as-yet unnoticed, non-BP traits) independently, while the separate alleles with balancing effects on BP have been fixed on a haplotype. In the BP-associated region at $12 \mathrm{q} 21.3$, for example, there exists a potential candidate gene for CAD, GALNT4, adjacent to $A T P 2 B 1$; the GALNT4 gene, encoding the polypeptide $\mathrm{N}$-acetylgalactosaminyltransferase 4 , plays a role in modifying glycoproteins, which have critical function in both platelet and endothelial cells. ${ }^{26}$ The other possibility is that a 
single causal variant accounts for the observed associations with multiple CAD risk phenotypes in a pleiotropic manner, as mentioned. One such example is the reported association of $\mathrm{P} 446 \mathrm{~L}$ variant in GCKR with raised TG and lower glucose levels, both of which are likely to be mediated by indirect increase in glucokinase activity. ${ }^{27}$

A number of prospective epidemiological studies have established the relation between BP elevation and the risk of incident CAD. ${ }^{6,28}$ This may largely support causal inferences about the effect of BP elevation on CAD. Nevertheless, given the complex nature of $\mathrm{BP}$ regulation, it is of interest to assess its causal relevance to CAD by using naturally occurring genetic variants as instruments. Using these 9 genetic variants, which are among those most significantly associated with BP in east Asian people, we tested the hypothesis that genetically raised $\mathrm{BP}$ might increase the risk for $\mathrm{CAD}$, in a manner similar to a previous study. ${ }^{3} \mathrm{We}$ investigated the association of genetic risk score for BP with CAD in 4,399 cases and 7,672 controls of Japanese descent. In the previous meta-analysis involving European and south Asian ancestry (a total of 30,657 cases and 71,911 controls), ${ }^{3}$ which included the CARDIoGRAM ${ }^{7}$ data set and 2 additional samples, the genetic risk score for BP (using 29 SNPs from 28 unique loci) was positively associated with $\mathrm{CAD}\left(\mathrm{P}=8.1 \times 10^{-29}\right)$. Discrepancies in the estimated, unit effect sizes between the 2 studies $(0.100$, previous GWA meta-analysis $^{3}$ vs. 0.049 , present study; $\ln$ (odds) per SD of genetic risk score) may be due, in part, to the counteractive effects of the alleles at $A T P 2 B 1$ on CAD association, which seem to be prominent in east Asian people, although CAD association itself was similarly detectable in European people at $A T P 2 B 1$ rs $17249754(\mathrm{P}=0.013)$, in a direction inconsistent with its effect on BP. ${ }^{8}$ Further investigation is warranted to evaluate such inter-population discrepancies in the estimated effect sizes for genetic risk score, using the same set of BP SNPs among different ethnic groups, although care has to be taken, given the possible presence of ethnic differences in LD structure and allele frequency. Also, it needs to be determined whether the genetic mechanism at the $A T P 2 B 1$ locus involves disrupted regulation of a single gene (eg, $A T P 2 B 1)$ with pleiotropic effects or more than 1 genes with mutually discrete effects on $\mathrm{BP}$ and $\mathrm{CAD}$, by pinpointing the true functional variant (or variants) in the target region of association and by performing a combination of gene function experiments in vivo and in vitro.

Whether individual BP loci exert genetic effects on CAD through non-BP-mediated pathways genetically determined or not, SNP-related BP effects cannot be neglected, although average SNP effects on BP are relatively modest, that is, approximately $1 \mathrm{mmHg}$ for SBP. A meta-analysis of pharmacological studies has shown that a mean BP decrease of $1.04 \mathrm{mmHg}$ may reduce CAD risk by only $2.3 \%,{ }^{29}$ but it is possible that SNP-related BP effects capture a lifetime exposure to a difference in BP, whereas clinical studies reflect medium-term effects. ${ }^{8}$ This will lead to potential underestimation of the true risk mediated by genetic effects on $\mathrm{BP}$ and suggests that the small sizes of SNP-related BP effect may have clinical relevance.

\section{Conclusions}

A substantial proportion of genetic variants associated with $\mathrm{BP}$ are also associated with the risk of CAD in east Asian subjects, whereas the effect sizes are not necessarily correlated between the 2 traits. Polymorphisms at the ATP2B1 locus are found to be associated with $\mathrm{CAD}$ in the direction opposite to what is generally recognized for BP in the epidemiological studies. These findings provide evidence for the inherently complex nature of hypertension and cardiovascular complications at the level of individual susceptibility genes.

\section{Acknowledgments}

We thank all the people who have continuously supported the Hospitalbased Cohort Study at the National Center for Global Health and Medicine, the Amagasaki Study, the Kyushu University Fukuoka Cohort Study, and the KING Study. We also thank Drs Akihiro Fujioka, Suminori Kono, Ken Sugimoto, Kei Kamide, Hiromi Rakugi, Yukio Yamori, Toshio Ogihara, and the many physicians of the participating hospitals and medical institutions for their assistance in collecting the DNA samples and accompanying clinical information. We thank the members of the AGEN Consortium for kindly sharing the summary data of their metaanalysis.

\section{Disclosures}

Grants: Grant of National Center for Global Health and Medicine; and the Ministry of Health Labour and Welfare.

\section{References}

1. Ehret GB. Genome-wide association studies: Contribution of genomics to understanding blood pressure and essential hypertension. $\mathrm{Curr}$ Hypertens Rep 2010; 12: 17-25.

2. Munroe PB, Barnes MR, Caulfield MJ. Advances in blood pressure genomics. Circ Res 2013; 112: 1365-1379.

3. International Consortium for Blood Pressure Genome-Wide Association Studies, Ehret GB, Munroe PB, Rice KM, Bochud M, Johnson $\mathrm{AD}$, Chasman DI, et al. Genetic variants in novel pathways influence blood pressure and cardiovascular disease risk. Nature 2011; 478: 103- 109 .

4. Miura K, Nagai M, Ohkubo T. Epidemiology of hypertension in Japan: Where are we now? Circ J 2013; 77: 2226-2231.

5. Hata J, Kiyohara Y. Epidemiology of stroke and coronary artery disease in Asia. Circ J 2013; 77: $1923-1932$.

6. Bangalore S, Kumar S, Volodarskiy A, Messerli FH. Blood pressure targets in patients with coronary artery disease: Observations from traditional and Bayesian random effects meta-analysis of randomised trials. Heart 2013; 99: 601-613.

7. Preuss M, König IR, Thompson JR, Erdmann J, Absher D, Assimes TL, et al. Design of the Coronary ARtery DIsease Genome-Wide Replication And Meta-Analysis (CARDIoGRAM) Study: A Genomewide association meta-analysis involving more than 22000 cases and 60000 controls. Circ Cardiovasc Genet 2010; 3: 475-483.

8. Lieb W, Jansen H, Loley C, Pencina MJ, Nelson CP, Newton-Cheh $\mathrm{C}$, et al. Genetic predisposition to higher blood pressure increases coronary artery disease risk. Hypertension 2013; 61: 995-1001.

9. Kato N, Takeuchi F, Tabara Y, Kelly TN, Go MJ, Sim X, et al. Metaanalysis of genome-wide association studies identifies common variants associated with blood pressure variation in east Asians. Nat Genet 2011; 43: 531-538.

10. Takeuchi F, Yokota M, Yamamoto K, Nakashima E, Katsuya T, Asano H, et al. Genome-wide association study of coronary artery disease in the Japanese. Eur J Hum Genet 2012; 20: 333-340.

11. Lee JY, Lee BS, Shin DJ, Park KW, Shin YA, Kim KJ, et al. A genome-wide association study of a coronary artery disease risk variant. J Hum Genet 2013; 58: 120-126.

12. Tsuchihashi-Makaya M, Serizawa M, Yanai K, Katsuya T, Takeuchi F, Fujioka A, et al. Gene-environmental interaction regarding alcohol-metabolizing enzymes in the Japanese general population. Hypertens Res 2009; 32: 207-213.

13. Nanri A, Yoshida D, Yamaji T, Mizoue T, Takayanagi R, Kono S. Dietary patterns and C-reactive protein in Japanese men and women. Am J Clin Nutr 2008; 87: 1488-1496.

14. Cho YS, Chen CH, Hu C, Long J, Ong RT, Sim X, et al. Metaanalysis of genome-wide association studies identifies eight new loci for type 2 diabetes in east Asians. Nat Genet 2011; 44: 67-72.

15. Wen W, Cho YS, Zheng W, Dorajoo R, Kato N, Qi L, et al. Metaanalysis identifies common variants associated with body mass index in east Asians. Nat Genet 2012; 44: 307-311.

16. Purcell S, Neale B, Todd-Brown K, Thomas L, Ferreira MA, Bender D, et al. PLINK: A tool set for whole-genome association and population-based linkage analyses. Am J Hum Genet 2007; 81: 559575 .

17. Miura K, Nakagawa H, Ohashi Y, Harada A, Taguri M, Kushiro T, 
et al. Four blood pressure indexes and the risk of stroke and myocardial infarction in Japanese men and women: A meta-analysis of 16 cohort studies. Circulation 2009; 119: 1892-1898.

18. Lewington S, Thomsen T, Davidsen M, Sherliker P, Clarke R. Regression dilution bias in blood total and high-density lipoprotein cholesterol and blood pressure in the Glostrup and Framingham prospective studies. J Cardiovasc Risk 2003; 10: 143-148.

19. Lu X, Wang L, Chen S, He L, Yang X, Shi Y, et al. Genome-wide association study in Han Chinese identifies four new susceptibility loci for coronary artery disease. Nat Genet 2012; 44: 890-894.

20. Schunkert H, König IR, Kathiresan S, Reilly MP, Assimes TL, Holm $\mathrm{H}$, et al. Large-scale association analysis identifies 13 new susceptibility loci for coronary artery disease. Nat Genet 2011; 43: 333-338.

21. CARDIoGRAMplusC4D Consortium, Deloukas P, Kanoni S, Willenborg C, Farrall M, Assimes TL, Thompson JR, et al. Largescale association analysis identifies new risk loci for coronary artery disease. Nat Genet 2013; 45: 25-33.

22. Wen W, Zheng W, Okada Y, Takeuchi F, Tabara Y, Hwang JY, et al. Meta-analysis of genome-wide association studies in East Asianancestry populations identifies four new loci for body mass index. Hum Mol Genet 2014; 23: 5492-5504.

23. Velasquez-Mieyer PA, Cowan PA, Arheart KL, Buffington CK, Spencer KA, Connelly BE, et al. Suppression of insulin secretion is associated with weight loss and altered macronutrient intake and preference in a subset of obese adults. Int J Obes Relat Metab Disord 2003; 27: 219-226.

24. Kobayashi Y, Hirawa N, Tabara Y, Muraoka H, Fujita M, Miyazaki $\mathrm{N}$, et al. Mice lacking hypertension candidate gene ATP2B1 in vascular smooth muscle cells show significant blood pressure elevation. Hypertension 2012; 59: 854-860.

25. Wang Y, Zhang Y, Li Y, Zhou X, Wang X, Gao P, et al. Common variants in the ATP2B1 gene are associated with hypertension and arterial stiffness in Chinese population. Mol Biol Rep 2013; 40: $1867-1873$.

26. O'Halloran AM, Patterson CC, Horan P, Maree A, Curtin R, Stanton $\mathrm{A}$, et al. Genetic polymorphisms in platelet-related proteins and coronary artery disease: Investigation of candidate genes, including $\mathrm{N}$-acetylgalactosaminyltransferase 4 (GALNT4) and sulphotransferase 1A1/2 (SULT1A1/2). J Thromb Thrombolysis 2009; 27: 175184.
27. Beer NL, Tribble ND, McCulloch LJ, Roos C, Johnson PR, OrhoMelander M, et al. The P446L variant in GCKR associated with fasting plasma glucose and triglyceride levels exerts its effect through increased glucokinase activity in liver. Hum Mol Genet 2009; 18: 4081-4088.

28. Lewington S, Clarke R, Qizilbash N, Peto R, Collins R; Prospective Studies Collaboration. Age-specific relevance of usual blood pressure to vascular mortality: A meta-analysis of individual data for one million adults in 61 prospective studies. Lancet 2002; 360: $1903-1913$.

29. Staessen JA, Gasowski J, Wang JG, Thijs L, Den Hond E, Boissel JP, et al. Risks of untreated and treated isolated systolic hypertension in the elderly: Meta-analysis of outcome trials. Lancet 2000; 355: $865-872$.

30. Teramoto T, Sasaki J, Ueshima H, Egusa G, Kinoshita M, Shimamoto $\mathrm{K}$, et al. Japan Atherosclerosis Society (JAS) Committee for Epidemiology and Clinical Management of Atherosclerosis: Diagnostic criteria for dyslipidemia. Executive summary of Japan Atherosclerosis Society (JAS) guideline for diagnosis and prevention of atherosclerotic cardiovascular diseases for Japanese. J Atheroscler Thromb 2007; 14: $155-158$.

\section{Supplementary Files}

\section{Supplementary File 1}

Figure S1. Regional association plots of 3 loci (A-C).

Figure S2. Forest plots showing the results for the 9 single nucleotide polymorphisms (SNPs) examined in the validation samples (Japanese tier 2) as well as genome-wide association (GWA)-scanned samples.

Figure S3. Predicted and observed effect sizes for the association of each blood pressure (BP)-associated single nucleotide polymorphism (SNP) with coronary artery disease (CAD).

Table S1. Effects of BP-associated SNPs on CAD in 2-tiered Japanese sample

Appendix S1. AGEN Consortium

Please find supplementary file(s); http://dx.doi.org/10.1253/circj.CJ-14-0841 